\title{
POLYNEUROPATHIES AND CNS PROTEIN METABOLISM. I. DESCRIPTION OF THE ACRYLAMIDE SYNDROME IN RATS
}

\author{
L. GIPON, P. SCHOTMAN, F. G. I. JENNEKENS* AND
}

W. H. GISPEN

Institute of Molecular Biology, Division of Molecular Neurobiology, University of of Utrecht, Padualaan 8, Utrecht, and *University Hospital, Department of Neurology, Utrecht, The Netherlands

Accepted for publication 24 October 1976

Gipon L., Schotman P., Jennekens F.G.I. \& Gispen W.H. (1977) Neuropathology and Applied Neurobiology 3, 115-123

Polyneuropathies and CNS protein metabolism. I. Description of the acrylamide syndrome in rats

Behavioural, histological and metabolic studies were performed on acrylamideintoxicated rats. Treated rats showed disturbed food and water consumption accompanied by loss of body weight. In addition, in an open field test they displayed less ambulation and rearing activity than controls, and had severe difficulties in balancing on a rotating rod. The last test gives a reliable indication of the acrylamide-induced disorder before the onset of histological changes. In the discussion it is suggested that the data question the neurotoxic selectivity of acrylamide.

\section{Introduction}

Acrylamide $\left(\mathrm{CH}_{2}=\mathrm{CHCONH}_{2}\right)$ is used in the production of high molecular weight polymers (Bikales, 1973). Human cases of peripheral neuropathy due to occupational exposure have occurred (Garland \& Patterson, 1967; Auld \& Bedwell, 1967) and the clinical and histological features of this neuropathy have been extensively studied and recently reviewed by Spencer \& Schaumberg (1974a; b). The neuropathy is characterized by distal axonal degeneration (Prineas, 1969; Schaumberg, Wisniewski \& Spencer, 1974), but the underlying mechanism is unknown.

Acrylamide is often considered as specifically neurotoxic, and relatively little attention has been paid to its general systemic effects. It is, however, a highly reactive chemical interfering with many molecular processes. In any attempt to unravel its mechanism of action the chemical factors concerned must be related to the various stages of intoxication.

In the present study some of the toxic effects of acrylamide on rats are analysed, particularly their food and water consumption during the intoxication, and their 
behaviour in an open field and in motor-performance tests. These findings have been correlated with the morphology of the peripheral nerves. In the companion paper the stages of the acrylamide syndrome are related to changes in protein metabolism in the nervous system.

\section{Materials and methods}

\section{Animals and treatment schedules}

Female rats of an inbred Wistar strain (150-170 g) were used. Acrylamide ( $4 \times$ cryst., Serva, Heidelberg) was dissolved in saline and given intraperitoneally $(1 \mathrm{ml} / 100 \mathrm{~g}$ body weight) either in high doses (50 $\mathrm{mg} / \mathrm{kg}$ daily) or in relatively low doses $(20 \mathrm{mg} / \mathrm{kg}$ daily or $50 \mathrm{mg} / \mathrm{kg}$ each other day). Control rats received saline instead of acrylamide.

\section{Histology and histochemistry}

Cryostat transverse sections of the anterior tibial muscle were used for routine histological and enzyme histochemical staining. Nerve fibres were shown by the methylene blue method. Pieces of peroneal and sciatic nerves were fixed in cacodylate-buffered glutaraldehyde, postfixed with $\mathrm{OsO}_{4}$ and embedded in Epon. Semi-thin $(2 \mu \mathrm{m})$ sections were stained with toluidine blue. Cryostat transverse sections of the lower half of the lumbar spinal cord were stained for the enzymes NADH-tetrazolium reductase, SDH and $\alpha$-GDP and of the lysosomal enzyme acid phosphatase. Other sections were stained with cresyl violet and luxol fast blue.

\section{Open field behaviour}

An open field designed according to Broadhurst (1960) was used. Two parameters of exploratory and/or locomotory activity were measured (a) ambulation, scored by counting the number of floor units entered by the rat and (b) rearing, measured by counting how often a rat reached up by standing on its hind paws, with or without placing its fore paws against the field wall. The rats were tested once every day in a 3 min session. The data (Table 1) were expressed as median values per day treatment group.

\section{Rotarod}

This device was similar to that described by Kaplan \& Murphy (1972). It consisted of a horizontal wooden $\operatorname{rod}(7.5 \mathrm{~cm}$ in diameter) $35 \mathrm{~cm}$ above a grid floor. On the rod were three aluminium plates, limiting two parts of the rod, each $18 \mathrm{~cm}$ long. If a rat fell from the rod and made contact with the grid floor an electric shock of $0.25 \mathrm{~mA}$ was delivered (d.c., scrambled, $10 \mathrm{~s}$ ). Rotation speed was $8 \mathrm{rev} / \mathrm{min}$. The performance was measured daily in three trials of $2 \mathrm{~min}$ (intertrial interval $20 \mathrm{~min}$ ). All rats had been initially trained to be able to remain for $2 \mathrm{~min}$ on the rotating rod (2-3 training sessions). After completing the 2 min period or the $10 \mathrm{~s}$ punishment, the rats were returned to their cages. The average time spent per rat on the rotarod over the three trials was computed.

\section{Food and water consumption}

To measure daily food and water intake, rats were placed singly in metabolism cages (UNO, ACME cage type AC-5062; animal space in $\mathrm{mm}: 108 \times 203)$, and kept in an air-conditioned room $\left(24^{\circ} \mathrm{C}\right.$, humidity $50 \%$ ) on a 8.00 a.m. -8.00 p.m. day-night lighting cycle. Daily, between 10 and 12 a.m. the rats were weighed and their food and water intake and urine and faeces production were measured. Intake or production per $100 \mathrm{~g}$ body weight are summated per rat over the total treatment period. In Table 2 mean values per treatment group are given. 


\section{Results}

\section{Histology and histochemistry}

Fourteen rats given acrylamide (50 mg/kg every other day) and six controls were examined. Treated rats were killed after cumulative doses of 200,400 and $550 \mathrm{mg} / \mathrm{kg}$ body weight. No histological or histochemical differences between treated and control rats in fibre diameter in the anterior tibial muscles were found.

Intramuscular motor nerve fibres or terminals were not affected by a cumulative dose of $200 \mathrm{mg} / \mathrm{kg}$. At $400 \mathrm{mg} / \mathrm{kg}$ occasional motor nerve terminals seemed blunt and somewhat swollen. At $550 \mathrm{mg} / \mathrm{kg}$ many motor nerve fibres and motor nerve terminals
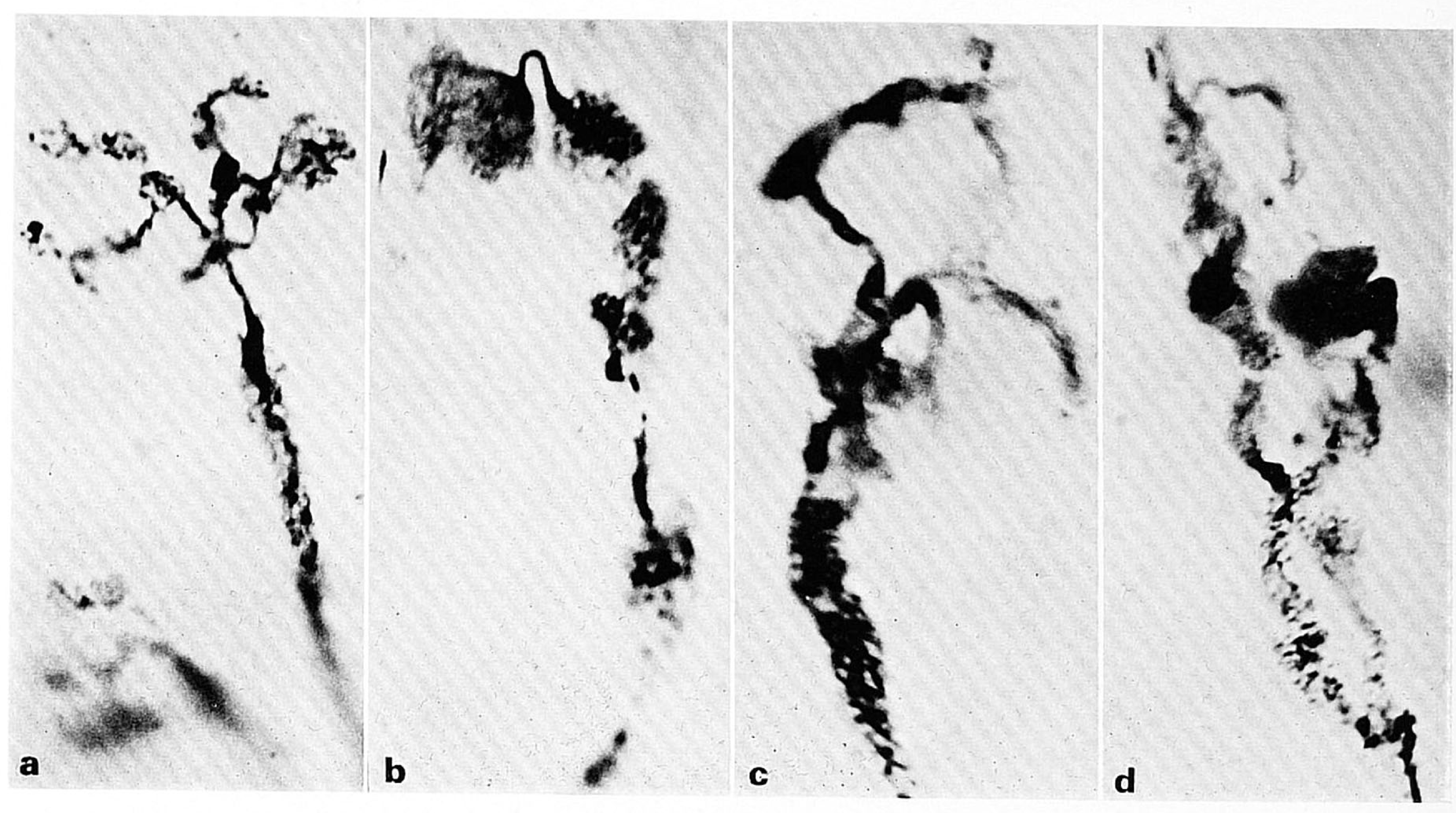

Figure 1. Terminal axons and arborizations in rat muscle. Methylene blue. $\times 1000$.

a From control animal.

b, c and d From intoxicated animals. Cumulative dose of acrylamide $550 \mathrm{mg} / \mathrm{kg}$. The axons and the branches of the arborizations show irregularly swollen segments.

showed irregular swellings, while others seemed normal (Figure 1). The first signs of degeneration in the peripheral nerves were seen in animals given $400 \mathrm{mg} / \mathrm{kg}$. Occasional large nerve fibres were affected. At a cumulative dose of $550 \mathrm{mg} / \mathrm{kg}$ approximately $50-70 \%$ of the large nerve fibres were involved, but some small fibres also showed changes. The changes were essentially the same as those described by Schaumberg et al. (1974). Degeneration was more obvious in peroneal than in sciatic 
nerves at $400 \mathrm{mg} / \mathrm{kg}$, but no differences between these two levels were seen after 550 $\mathrm{mg} / \mathrm{kg}$. No histological abnormalities were found in the spinal cord and the enzyme histochemical findings were normal.

\section{Acrylamide and open field behaviour}

The methods used provided an opportunity to observe the occurrence of abnormal behaviour, when done by an experienced observer. Rats given either $20 \mathrm{mg} / \mathrm{kg}$ or $50 \mathrm{mg} / \mathrm{kg}$ acrylamide daily were observed from the day after the first injection. Immediately after a 3 min session the next acrylamide or saline injection was given. From Table 1 it can be seen that $50 \mathrm{mg} / \mathrm{kg}$ daily rapidly influenced behaviour.

Table 1. Effect of acrylamide on ambulation and rearing of rats in the open field test, expressed as the median score obtained ( \pm range) in each 3 min observation period. Number of animals in each test in brackets

\begin{tabular}{|c|c|c|c|c|c|c|}
\hline \multirow[b]{2}{*}{$\begin{array}{l}\text { Day of } \\
\text { dosing } \\
\quad(i . p . \\
\text { injection })\end{array}$} & \multicolumn{3}{|c|}{ Ambulation } & \multicolumn{3}{|c|}{ Rearing } \\
\hline & $\begin{array}{c}\text { Control } \\
\text { (11) }\end{array}$ & $\begin{array}{c}\text { Acrylamide } \\
20 \mathrm{mg} / \mathrm{kg} / \text { day } \\
(6)\end{array}$ & $\begin{array}{c}\text { Acrylamide } \\
50 \mathrm{mg} / \mathrm{kg} / \text { day } \\
\text { (5) }\end{array}$ & $\begin{array}{c}\text { Control } \\
\text { (11) }\end{array}$ & $\begin{array}{c}\text { Acrylamide } \\
20 \mathrm{mg} / \mathrm{kg} / \text { day } \\
(6)\end{array}$ & $\begin{array}{c}\text { Acrylamide } \\
50 \mathrm{mg} / \mathrm{kg} / \text { day } \\
\text { (5) }\end{array}$ \\
\hline \multicolumn{7}{|l|}{1} \\
\hline 2 & $73 \pm 24$ & $60 \pm 41$ & $62 \pm 28$ & $11 \pm 22$ & $8 \pm 16$ & $5 \pm 7^{*}$ \\
\hline 3 & $69 \pm 49$ & $72 \pm 76$ & $30 \pm 52 *$ & $9 \pm 15$ & $7 \pm 14$ & $1 \pm 6^{*}$ \\
\hline 4 & $54 \pm 66$ & $51 \pm 36$ & $9 \pm 26 *$ & $4 \pm 13$ & $9 \pm 11$ & $0 \pm 2^{*}$ \\
\hline 5 & $70 \pm 64$ & $61 \pm 82$ & $23 \pm 30^{*}$ & $8 \pm 22$ & $8 \pm 13$ & $0 \pm 1^{*}$ \\
\hline 6 & $51 \pm 71$ & $29 \pm 70$ & $20 \pm 20^{*}$ & $6 \pm 15$ & $5 \pm 9$ & $0 \pm 2^{*}$ \\
\hline 7 & $49 \pm 45$ & $22 \pm 53$ & $9 \pm 12^{*}$ & $7 \pm 14$ & $3 \pm 8$ & $0 \pm 0^{*}$ \\
\hline 8 & $48 \pm 62$ & $45 \pm 58$ & $13 \pm 5^{*}$ & $11 \pm 18$ & $6 \pm 9$ & $0 \pm 0^{*}$ \\
\hline 9 & $59 \pm 51$ & $54 \pm 48$ & & $9 \pm 16$ & $5 \pm 8^{*}$ & \\
\hline
\end{tabular}

* Probability $P<0.05$ (Mann-Whitney $U$-test).

Even after one i.p. injection of $50 \mathrm{mg} / \mathrm{kg}$ on the subsequent day a lower rearing frequency was noted. After the second injection of $50 \mathrm{mg} / \mathrm{kg}$ a marked reduction in ambulation was apparent which remained throughout the observation period. After three injections the rats hardly reared at all. Decrease in rearing activity consistently preceded signs of ataxia in the hind paws (from about $250 \mathrm{mg} / \mathrm{kg}$ ), and splaying of the hind limbs preceded signs of muscle weakness. Behavioural deterioration paralleled decrease in motor activity. Rats treated with $20 \mathrm{mg} / \mathrm{kg}$ daily for the first 8 days showed behavioural patterns indistinguishable from controls. A decrease in rearing activity on the ninth day suggested that behavioural changes similar to the $50 \mathrm{mg} / \mathrm{kg}$ group might have developed had the observation period been prolonged. In all groups, both treated and control, relatively little grooming occurred. 


\section{Rotarod}

Control rats were invariably able to stay on the rod when tested throughout the experimental period, but those chronically treated with acrylamide fell from the rod before completing the 2 min balancing period (Figure 2). Those receiving higher daily doses failed to complete the $2 \mathrm{~min}$ balancing period at a lower cumulative dose (Figure 2a). Thus, after $50 \mathrm{mg} / \mathrm{kg}$ daily, the first significant change occurred at a cumulative dose of $300 \mathrm{mg} / \mathrm{kg}$, while with $20 \mathrm{mg} / \mathrm{kg}$ the same changes were seen after $380 \mathrm{mg} / \mathrm{kg}$.

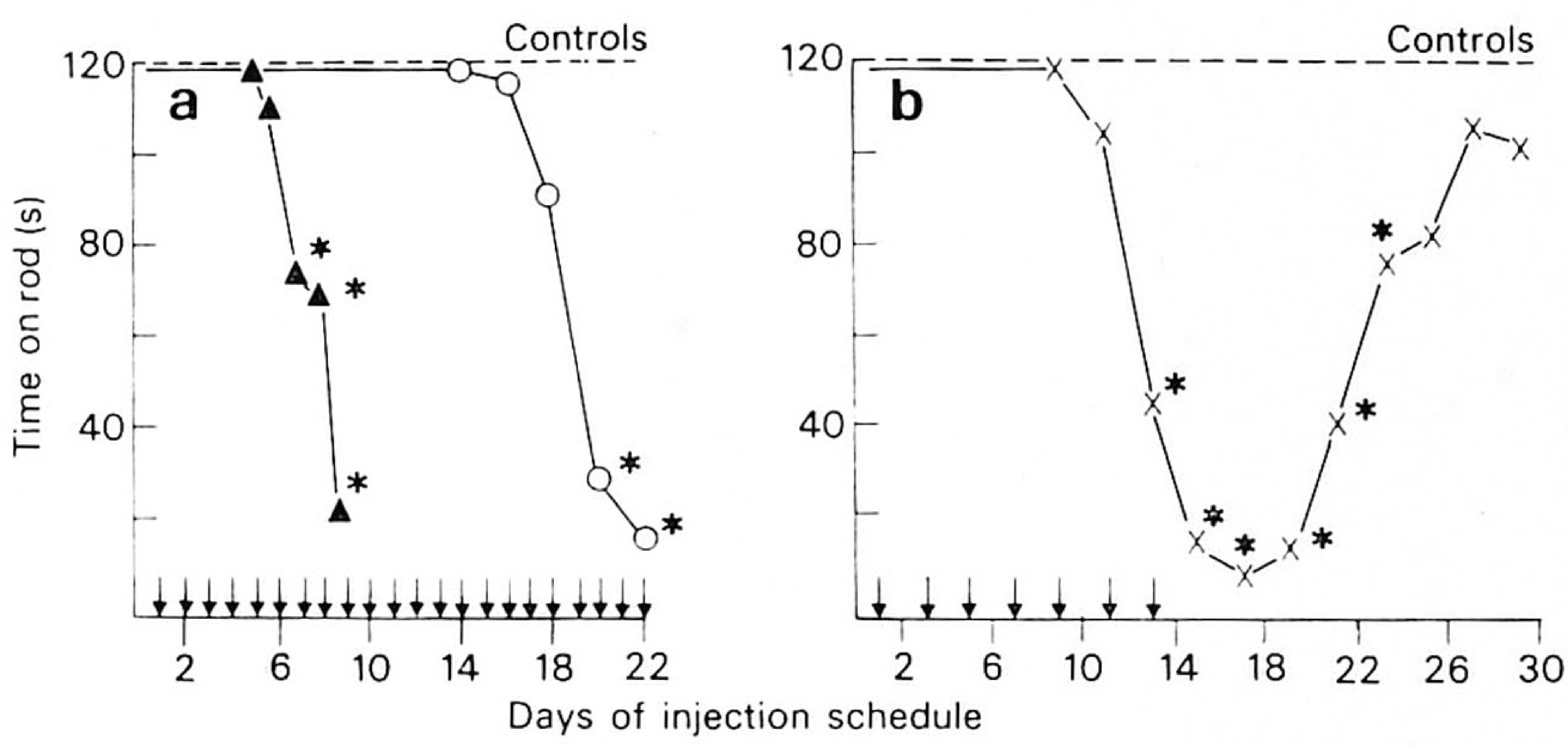

Figure 2. Median performance of rats on rotarod up to $2 \mathrm{~min}$. Arrows indicate time of injection of acrylamide.

a $\Delta-\mathbf{\Delta}, 50 \mathrm{mg} / \mathrm{kg} /$ day, median results of 6 rats, $\bigcirc-0,20 \mathrm{mg} / \mathrm{kg} /$ day, mean results of 8 rats.

b $\times-\ldots, 50 \mathrm{mg} / \mathrm{kg}$ alternate days to a total of $350 \mathrm{mg} / \mathrm{kg}$, then allowed to recover, median results of 7 rats.

* Probability, $P<0 \cdot 05$, Mann-Whitney $U$-test.

In one experiment seven rats were treated with $50 \mathrm{mg} / \mathrm{kg}$ every other day and after a cumulative dose of $350 \mathrm{mg} / \mathrm{kg}$ they were allowed to recover; their performance on the rotarod was followed. Their intoxication was reversible since their performance on the rotarod returned to normal after 10-12 days (Figure $2 \mathrm{~b}$ ).

\section{Acrylamide and food and water consumption}

The effect of different daily doses of acrylamide giving approximately the same cumulative dose $(450 \mathrm{mg} / \mathrm{kg})$ on body weight, food and water intake, and faeces and urine production is shown in Table 2. Daily treatment of eight rats with $20 \mathrm{mg} / \mathrm{kg}$ for 22 days (cumulative dose $440 \mathrm{mg} / \mathrm{kg}$ ) led to a small reduction of body growth and faeces production, and a tendency to a lower food intake, while urine production increased probably from a higher water intake; $50 \mathrm{mg} / \mathrm{kg}$ given daily (cumulative dose $450 \mathrm{mg} /$ $\mathrm{kg}$ ) to six rats led to a marked reduction in their growth paralleled by a lower food intake and faeces production, but no effects on water intake occurred. 
Table 2. Effect of acrylamide on daily food and water intake and excretory production ( \pm s.e.m.)

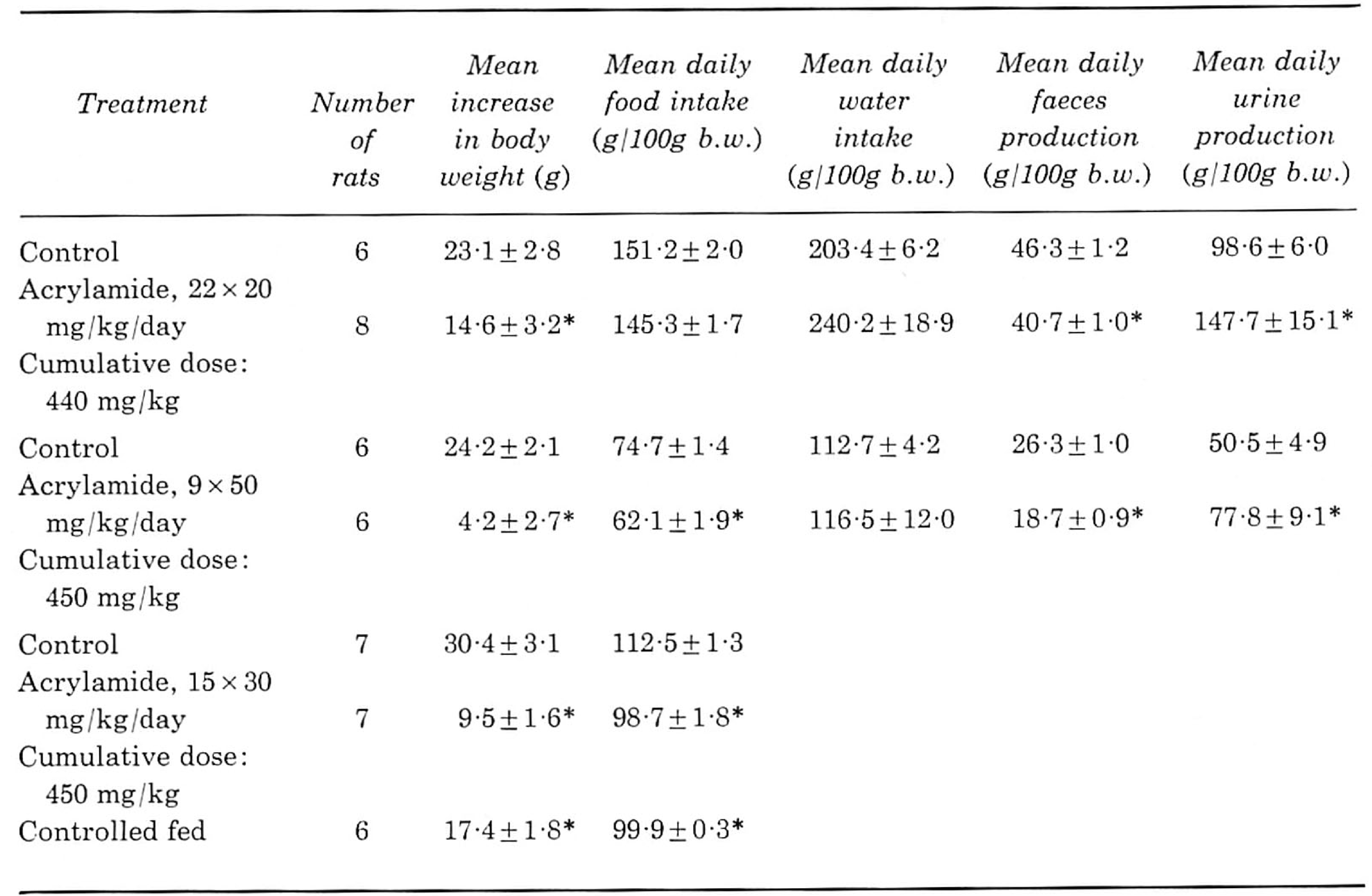

* Probability, $P<0.05$ (Student $t$-test).

These experiments indicated that even from the first injection of these doses of acrylamide, changes in food and water balance occurred. To gain more insight into this process a further group of rats was treated daily with $30 \mathrm{mg} / \mathrm{kg}$ and compared with a pair-fed control group. With doses of $30 \mathrm{mg} / \mathrm{kg}$ for 15 days moderate effects on food intake and body weight were produced when compared with saline-treated rats who had food ad libitum. Despite a parallel reduction in food intake pair-fed controls kept a better growth rate than their intoxicated counterparts. Moreover, pair-fed control rats invariably were able to balance on the rotating rod, and thus the impaired performance of this test after acrylamide treatment is more likely to be related to the development of the neuropathy, rather than to any general factor.

\section{Discussion}

Morphological changes due to acrylamide occur chiefly in the neurites of peripheral sensory and motor neurons, and electron-microscopical studies have shown only slight changes in the nerve cell bodies (Prineas, 1969). There may be, in addition, changes in the dorsal spinocerebellar tracts, and in the mossy fibres in the granular layer of the cerebellar vermis, as well as in cell bodies of the nucleus gracilis (Ghetti, Wisniewski, Cook \& Schaumberg, 1973). Clinical signs indicate that the autonomic 
system may also be involved (McCollister, Oyen \& Rowe, 1964; Fullerton \& Barnes, 1966). The temporal sequence of the events in the distal peripheral nerve fibres has been carefully analysed by Schaumberg et al. (1974). Thus, large axons are more vulnerable than small axons and distal nerve fibres supplying Pacinian corpuscles are damaged before distal primary sensory fibres of muscle spindles, and these changes are followed by distal motor nerve fibre degeneration. Axonal regeneration following crush injury may be inhibited or slowed by acrylamide (Morgan-Hughes, Sinclair \& Durston, 1974) and the neuropathy induced by acrylamide is reversible (Spencer \& Schaumberg, 1974b).

In our studies the cell bodies of the peripheral nerves appeared normal without increase in the lysosomal acid phosphatase activity, nor were changes in aerobic metabolism as judged by oxidative enzyme activities within the cell bodies found. Peripherally the neuromuscular junctions appeared unaffected at the light-microscopical level at a cumulative dose of $200 \mathrm{mg} / \mathrm{kg}$, while motor performance was adequate. At a cumulative dose of $400 \mathrm{mg} / \mathrm{kg}$, however, changes in the neuromuscular junctions were still very few, while motor performance was now defective (Figure 2). It is unlikely, however, that this was due only to motor terminal changes, for peripheral sensory nerves are known to be affected before motor nerves, and moreover, degenerating nerve fibres in the peripheral nerves were found at this time. At a total dose of $550 \mathrm{mg} / \mathrm{kg}$ the distal motor nerve fibres were extensively altered (Figure 1).

The reversibility of the acrylamide neuropathy is shown by the rotarod performance of intoxicated rats allowed to recover. These results thus show the rotarod to be a simple and accurate device to assess the state of intoxication uninfluenced by non-specific systemic factors, such as decrease in body weight. High daily doses of acrylamide produce rotarod failure at a lower cumulative dose than low daily doses, so that performance seems to depend more on cumulative than on daily dose.

However, behaviour and locomotor activity in the open field are not dependent only on peripheral nervous function, but reflect the animal's general well-being. With high daily doses $(50 \mathrm{mg} / \mathrm{kg}$ ) reduction in activity occurred from the second injection, but inadequate rotarod performance did not occur until a cumulative dose of $300 \mathrm{mg} /$ $\mathrm{kg}$. It is, therefore, improbable that the early decrease of ambulation is caused by peripheral nerve changes which became apparent in splaying out of the hind limbs only after five or six injections.

That acrylamide also interferes with general metabolism is shown by excretory products and food and water consumption. Thus, urine output increased in intoxicated rats both at high and low daily doses of acrylamide, but while there was a tendency to a higher water consumption on the low daily dose $(20 \mathrm{mg} / \mathrm{kg})$, no such tendency was found at high daily doses, suggesting a disturbance of water balance. Fullerton \& Barnes (1966) reported that the most striking feature at necropsy after subacute acrylamide poisoning was the distended bladder. We have found in rats given $50 \mathrm{mg} /$ $\mathrm{kg}$ daily for 6 days a bladder enlargement by a factor 5 (Gipon, unpublished), and such findings are consistent with an autonomic neuropathy (McCollister et al., 1964). In animals treated with doses from 30 to $50 \mathrm{mg} / \mathrm{kg}$ daily, body growth and food intake were clearly diminished to a degree related to the daily dose. Retardation of body 
growth, however, was only partly due to decrease in food consumption as pair-fed controls showed a greater increase in body weight than their dosed counterparts (Table 2), suggesting that acrylamide hampers body growth by an as yet unidentified mechanism. Edwards (1975) reported that an analogue of acrylamide, methylene bisacrylamide, caused impairment of body growth, but did not cause a neuropathy. Further analysis of her data (Gipon \& Schotman, unpublished) confirmed that the decrease in body weight and food intake was similar to that in rats intoxicated by acrylamide, whereas rotarod performance remained adequate even at a cumulative dose of $800 \mathrm{mg} / \mathrm{kg}$ with this analogue. Thus, acrylamide cannot be regarded as acting exclusively on the nervous system, a conclusion supported by the observations in the companion paper that the incorporation of labelled leucine into heart muscle proteins is decreased during acrylamide intoxication.

\section{Acknowledgements}

The authors wish to thank H.J.W. Eelderink, H. Veldman and J.H. Brakkee for their skilled technical assistance and Dr D.E.J. Ebels for reading the manuscript.

L.G. acknowledges the receipt of a grant from the 'Prinses Beatrix Fonds'.

\section{References}

Auld R.B. \& Bedwell S.F. (1967) Peripheral neuropathy with sympathetic overactivity from industrial contact with acrylamide. Canadian Medical Association Journal 96, 652-654

Bikales N.M. (1973) Preparation of acrylamide polymers. In Water-soluble Polymers, ed. N.M. Bikales, Polymer Science and Technology 2, 213-225, Plenum Pless, New York

Broadhurst P.L. (1960) Experiments in psychogenetics: applications of biometrical genetics to the inheritance of behaviour. In Experiments in Personality, Vol. 1, ed. H.J. Eysenck, p. 30. Routledge \& Kegan Paul, London

EDwards P.M. (1975) Neurotoxicity of acrylamide and its analogues and effects of these analogues on acrylamide neuropathy. British Journal of Industrial Medicine 32, 31-38

Fullerton P.M. \& Barnes J.M. (1966) Peripheral neuropathy in rats produced by acrylamide. British Journal of Industrial Medicine 23, 210-221

Garland T.O. \& Patterson M.W.H. (1967) Six cases of acrylamide poisoning. British Medical Journal 4, 134-138

Ghetti B., Wisniewsin H.M., Cook R.D. \& Schaumberg H.H. (1973) Changes in the CNS after acute and chronic acrylamide intoxication. American Journal of Pathology 70, 78A

KAPLAN M.L. \& MURPHY S.D. (1972) Effect of acrylamide on rotarod performance and sciatic nerve $\beta$-glucuronidase activity of rats. Toxicology and Applied Pharmacology 22, 259-268

McCollister D.D., Oyen F. \& Rowe V.K. (1964) Toxicology of acrylamide. Toxicology and Applied Pharmacology 6, 172-181

Morgan-Hughes J.S., Sinclair S. \& Durston J.H.J. (1974) The pattern of peripheral nerve induced by nerve crush in rats with severe acrylamide neuropathy. Brain 97, 215-232

PRINEAS J. (1969) The pathogenesis of dying-back polyneuropathies, part II. An ultrastructural study of experimental acrylamide intoxication in the cat. Journal of Neuropathology and Experimental Neurology 28, 598-621 
Schaumberg H.H., Wisniewski H.M. \& Spencer P.S. (1974) Ultrastructural studies of the dying-back process. I. Peripheral nerve terminal and axon degeneration in systemic acrylamide intoxication. Journal of Neuropathology and Experimental Neurology 33, 260-284

Schotman P., Gipon L., Jennerens F.G.I. \& Gispen W.H. Polyneuropathies and CNS protein metabolism II. Changes in the incorporation rate of leucine during acrylamide intoxication. Neuropathology and Applied Neurobiology 3, 125-136

Spencer P.S. \& Schaumberg H.H. (1974a) A review of acrylamide neurotoxicity Part I. Properties, uses and human exposure. Canadian Journal of Neurological Sciences 1, 143-150

Spencer P.S. \& Schaumberg H.H. (1974b) A review of acrylamide neurotoxicity Part II. Experimental animal neurotoxicity and pathologic mechanisms. Canadian Journal of Neurological Sciences 1, $152-169$ 